\title{
Are your international salespeople culturally intelligent? The influence of cultural intelligence on adaptive selling behavior with B2B customers
}

\author{
Dr. David Kimber Camussetti * \\ Assistant Professor of Marketing \\ Universidad de los Andes, Chile \\ Monseñor Alvaro del Portillo 12455, Las Condes, Santiago, Chile \\ dkimber@uandes.cl \\ Dr. Rodrigo Guesalaga Trautmann \\ Dean School of Business and Economics \\ Universidad Finis Terrae \\ Av. Pedro de Valdivia 1509, Providencia, Santiago, Chile \\ rguesalaga@uft.cl \\ Dr. Michael Dickmann \\ Professor of International Human Resource Management \\ Cranfield University \\ School of Management \\ Cranfield, Bedfordshire, UK, MK43 0AL \\ m.dickmann@cranfield.ac.uk
}

Keywords: cultural intelligence; international business; sales management; adaptive selling behavior; intrinsic motivation; cultural distance.

The data that support the findings of this study are available from the corresponding author, upon reasonable request.

*: corresponding author 


\title{
Are your international salespeople culturally intelligent? The influence of cultural intelligence on adaptive selling behavior with B2B customers
}

\begin{abstract}
Purpose - This study aims to investigate cultural intelligence (CQ) as an antecedent of adaptive selling behavior (ASB) and cultural distance and intrinsic motivation as moderators in this relationship.
\end{abstract}

Design/methodology/approach - This research builds on a survey to 310 US-based international sales executives (ISE) and multiple regression analysis to test the hypotheses. Findings - The results show that CQ has a significant positive relationship with ASB, both as an aggregate construct and through its metacognitive, motivational, and behavioral facets. Also, intrinsic motivation moderates such relationship, whereas cultural distance does not.

Practical implications - The findings of this research suggest that supplier companies involved in international selling should consider the cultural intelligence of their salespeople for selection, training, and coaching.

Research limitations/implications - The study includes only a sample of US-based international salespeople in the B2B context, which limits the generalizability of the findings to salespeople from other countries or contexts.

Originality/value - This study makes an important contribution to the literature on both ASB and CQ by expanding the knowledge on how to manage international salespeople effectively, considering the conditions under which CQ effects are expected and how these vary in this context. 
Keywords cultural intelligence; international business; sales management; adaptive selling behavior; intrinsic motivation; cultural distance.

Paper type Research paper 


\section{Introduction}

Globalization and communication technologies have fostered the development of commercial relationships between companies from different countries, with an increase in cross-cultural interactions (Ivanova-Gongne, 2015; Lee and Sukoco, 2010; Murphy et al., 2020) ; yet, many of these encounters are not successful (Bartel-Radic and Giannelloni, 2017). This brings new challenges to companies in terms of adapting to different cultures, countries, and people (Ployhart and Weekley, 2015). Executives increasingly interact with those of different cultures (Ivanova-Gongne and Torkkeli, 2018) and cross-cultural competences are needed to sell effectively; in practice, however, these are rarely incorporated in selection and development programs for international sales executives (ISEs) (Hansen et al., 2011). Likewise, from a sales management perspective, supplier companies competing internationally are more likely to succeed if they are able and willing to adapt their selling approach to the customers' culture (Panagopoulus et al., 2011; Pornpitakpan, 2003). A clear understanding of the other side's culture affect the strategy to be used when negotiating international agreements (Brett, 2017).

In a literature review on international sales and sales management research, Schrock et al., (2018) identified adaptive selling as a topic of growing importance in the post-2000 period, relative to the pre-2000 period, highlighting the need for salespeople to adapt the communication to customers from different countries and cultural backgrounds. So far, the literature on sales management has identified several antecedents of adaptive selling behavior (ASB) (Weitz et al., 1986), such as salespeople's demographics, experience, customer orientation, cognitive styles, motivation, empathy, traits, skills and abilities, as well as thought self-leadership strategies (Alnakhli et al., 2020; Giacobbe et al., 2006; Harindranath et al., 2019; Jaramillo et al., 2007; 
Levy and Sharma, 1994; Limbu et al., 2016; Park and Holloway, 2003). However, our knowledge of why some salespeople are more effective than others in adapting their sales approach in cross-cultural settings is incomplete (Charoensukmongkol, 2020; Delpechitre and Baker, 2017; Pandey and Charoensukmongkol, 2019). Cultural intelligence (CQ) (Ang and Van Dyne, 2008; Earley and Ang, 2003), defined as “an individual's capability to function and manage effectively in culturally diverse settings" (Ang and Van Dyne, 2008, p.3) may contribute to answering such question. However, research on CQ has mostly focused on other contexts, like international students or expatriate executives, but not on sales executives (e.g., Engle and Crowne, 2014; Holtbrugge and Engelhard, 2015; Lin, et al., 2012; Malek and Budhwar, 2013). As Hansen et al. (2011, p. 243) indicate, “...our understanding of the means through which cross-cultural sales relationships are best managed is limited".

This research examines international sales executives' CQ as an antecedent of ASB, and cultural distance and intrinsic motivation as moderating factors of this relationship. Thus, we respond to the need to understand the conditions under which CQ effects are expected and how these vary (Ott and Michailova, 2018). The study contributes to existing knowledge on international sales in business markets by extending the research on the antecedents of ASB, showing CQ as a significant predictor of ASB. Also, we discuss human resource implications for sales management involved in international business in terms of selection, training, and management of ISEs.

\section{Theoretical background}

\section{Adaptive selling behavior and its antecedents}


Adaptive selling behavior (ASB) is defined as 'the altering of sales behavior during a customer interaction or across customer interactions based on perceived information about the nature of the selling situation' (Weitz et al., 1986, p. 175). By adapting their sales approach, salespeople have the opportunity to see a customer's reaction and respond to it, increasing the effectiveness of the sales effort (Spiro and Weitz, 1990; Weitz et al., 1986; Weitz, 1981). ASB has been found to be an important predictor of sales performance (Boorom et al., 1998; Franke and Park, 2006; Román and Iacobucci, 2010), and its relevance may be even greater in the international context where personal differences are likely to be more pronounced.

Previous literature reveals some interesting findings about the antecedents of ASB. In terms of the demographic characteristics of salespeople, and contrary to researchers' expectations, age, gender, and education do not appear to have a relevant direct influence on ASB (Dion et al., 1997; Franke and Park, 2006; Siguaw and Honeycutt, 1995). However, there is some evidence of interaction effects among demographic variables; for example, gender differences in ASB exist, but only in young salespeople, and formal education may affect ASB only among older sales executives (Levy and Sharma, 1994).

Scholars have also analyzed the role of sales experience in affecting ASB, expecting that by gaining experience, salespeople will be exposed to a wider variety of selling situations, and will develop a repertoire of selling strategies (Franke and Park, 2006). In fact, a majority of studies has shown a positive relationship between sales experience and ASB (e.g. Giacobbe et al., 2006; Franke and Park, 2006; Levy and Sharma, 1994; Robinson et al., 2002; Shoemaker and Johlke, 2002). In addition, customer orientation appears to be a significant predictor of ASB (Harindranath et al., 2019). 
Another stream of research has looked at salespeople's traits, skills, and abilities, as antecedents of ASB. Boorom et al. (1998) found that interaction involvement is positively related to ASB, whereas communication apprehension is negatively related to adaptive selling. Giacobbe et al. (2006) showed that both the ability to monitor the selling situation and the ability to modify self-behaviors and strategies were related to the intention to practice adaptive selling in non-structured selling settings. Simintiras et al. (2013) found that selling skills have a positive impact on the practice of adaptive selling, whereas Singh et al. (2017) showed that self-efficacy was a meaningful predictor of ASB. These results complement research that has found ASB to be positively related to androgyny, empathy, self-monitoring, and thought self-leadership strategies (Alnakhli et al., 2020; Eppler et al., 1998; Limbu et al., 2016; Spiro and Weitz, 1990). Furthermore, intrinsic motivation has been found to be a relevant determinant of ASB (Jaramillo et al., 2007; Román and Iacobucci, 2010; Spiro and Weitz, 1990).

\section{Cultural intelligence}

Cultural intelligence (CQ) has been conceptualized as an individual's capability to function and manage effectively in cross-cultural contexts, and it constitutes a type of intelligence which is different from cognitive, emotional, or social intelligence (Ang and Van Dyne, 2008; Earley, 2002; Earley and Ang, 2003). CQ is a culture-general and not culture-specific competence, as it offers a range of skills that are applicable to a broad variety of cultural contexts (Reiche et al., 2015). CQ has become an increasingly relevant aspect of intelligence due to globalization (Ott and Michailova, 2018; Van Dyne et al., 2009), and it is considered a distinctive type of cultural competence precisely because it is theoretically grounded in the framework of multiple intelligences (Adair et al., 2013). 
Cultural intelligence is composed of four facets: cognitive, metacognitive, motivational, and behavioral (Ang et al., 2007). Cognitive $C Q$ is the level of acquired cultural knowledge, in terms of norms, beliefs, facts, practices, and conventions in different cultures, which has been acquired from educational and personal experiences (Ang and Van Dyne, 2008; Bandura, 1999). Metacognitive $C Q$ refers to mental processes used by individuals to acquire and understand cultural knowledge, sometimes by questioning their cultural assumptions and adjusting their mental models accordingly (Ang and Van Dyne, 2008; Earley, 2002). It is the capacity of individuals to adapt and adjust their strategies to be culturally appropriate and to achieve desired outcomes in cross-cultural encounters. Motivational $C Q$ is the motivation to engage in culturally diverse relationships. It reflects the individuals' interest in learning and functioning in crosscultural situations (Crowne, 2006) and triggers the effort to functioning in novel cultural settings and helps individuals to overcome problems such as hostility or incomprehension (Ang and Van Dyne, 2008; Earley and Mosakowski, 2004). Finally, behavioral $C Q$ is the capability to exhibit appropriate verbal and nonverbal actions in cross-cultural interactions. It reflects the ability to acquire or adapt behaviors to a new culture or to a specific cultural interaction, which may include not displaying certain behaviors when it is necessary or adequate (Ang and Van Dyne, 2008; Crowne, 2006; Earley, 2002).

The four facets of CQ are qualitatively different and may or may not correlate with each other (Earley and Ang, 2003). For example, an individual may be knowledgeable about a specific culture, but may lack the ability to act upon this knowledge; or be motivated to engage in cross-cultural interaction, but may be unable to act in a way that leads to effective behavior. Therefore, it is reasonable to evaluate cultural intelligence not only as an aggregate construct, but 
also through its facets (Ang et al., 2007). We follow this approach in the development of the hypotheses.

\section{Conceptual model and hypotheses}

Figure 1 shows the conceptual model. Cultural intelligence is hypothesized to positively influence adaptive seling behavior, both as an aggregate construct and in its facets. Additionally, we expect cultural distance and intrinsic motivation to positively moderate the CQ-ASB relationship.

Figure 1 Conceptual model

INSERT FIGURE 1 HERE

\section{Cultural intelligence as an antecedent of adaptive selling behavior}

$C Q$ as an aggregate construct. We expect CQ to facilitate ASB in an international, cross-cultural context. Ang et al. (2007) found that individuals with higher CQ are able to make more accurate cultural judgments and show greater interactional adjustment than those with lower CQ. Likewise, Brett (2017) argue that culturally intelligent people respect cultural differences and should be able to manage them. Similarly, previous research has found that expatriates with higher CQ experienced greater cross-cultural adjustment than those with lower CQ (Lin et al. 2012; Malek and Budhwar, 2013; Templer et al., 2006).

This ample evidence about the relationship between CQ and cultural adaptation supports the idea of CQ positively affecting ASB in the international selling context. Hansen et al. (2011) argue that salespeople high in CQ would be more effective when facing international customers 
due to their better adaptation to their customers' cultural backgrounds, and define cultural adaptation (p. 245) as "one type of adaptive selling behavior", related to situations where salespeople modify their behaviors according to their customers' cultural setting. Moreover, in the context of Thai international salespeople, Charoensukmongkol (2020) finds a positive relationship between CQ and adaptive selling behaviors. Hence, we contend:

H1: Cultural intelligence is positively related to adaptive selling behavior.

$C Q$ as a construct of four facets. It might be that in different contexts, the relative importance of each CQ facet differs, and so there is a need to investigate 'where specific dimensions of CQ have special relevance to different outcomes' (Ang et al., 2007, p. 364).

Cognitive CQ - the level of acquired cultural knowledge - should inform ISEs about the key elements of a sales approach that need to be modified, in response to the customer's culture. Earley and Mosakowski (2004, p. 141) refer to it as the 'head', representing the rote learning about the beliefs, customs, and taboos of foreign cultures. The authors suggest that it would be unrealistic to expect customers to provide this information, either because of a reticence to explaining themselves to strangers or due to a lack of practice in looking at their own culture analytically. In the context of sales negotiations, Brett (2017) indicates that understanding the main characteristics of a culture can guide sales executives in what is normative, which facilitates the adaptation of the sales approach. Therefore, having high levels of cognitive CQ should guide ISEs to recognize specific elements of the customer's culture and act accordingly. Wiseman et al. (1989) argue that cultural knowledge reduces the risk of misunderstandings with people from a different culture, and increases intercultural competency. Then, we propose: 
$\mathrm{H} 2 \mathrm{a}$ : Cognitive CQ is positively related to adaptive selling behavior.

Metacognitive CQ - the mental processes used by individuals to acquire and understand cultural knowledge - should facilitate ISEs' adaptive selling behavior. Individuals high in metacognitive CQ acquire cultural information and adjust their mental models effectively, both before and during interactions (Ang and Van Dyne, 2008; Brislin et al., 2006; Triandis, 2006). It can be thought of as a strategy of learning how to learn skills (Earley and Peterson, 2004), and 'thinking about thinking, comprising the processes of monitoring and adjusting one's thoughts and strategies as one learns new skills' (Chua et al., 2012, p. 117). Thus, a salesperson high in metacognitive CQ will probably incorporate new information effectively during a sales encounter, and adjust their sales approach accordingly. Therefore, we posit:

$\mathrm{H} 2 \mathrm{~b}$ : Metacognitive CQ is positively related to adaptive selling behavior.

Motivational CQ - the motivation to engage in cross-cultural interactions - is expected to enhance the extent to which ISEs adapt the selling approach to a specific customer in a crosscultural setting. ASB requires the motivation to act upon the specific aspects of a selling situation and/or customer, which in our context means adjusting the selling approach to cultural differences. The willingness to apply one's capabilities, plus the attention and energy toward learning about functioning in a cross-cultural context, are critical (Earley and Ang, 2003; Johnson et al., 2006). Motivational CQ captures a self-efficacy belief in the ability to function in cross-cultural environments, as well as the intrinsic motivation to do so (Chen et al., 2012; 
Magnusson et al., 2013), which should increase the likelihood of initiating and maintaining an effort towards interacting with customers from a different culture and actively seeking crosscultural experiences ( $\mathrm{Ng}$ et al., 2009). This is consistent with previous research that has found a positive association between motivational CQ and different forms of cultural adaptation, such as cooperative behavior in intercultural negotiations (Imai and Gelfand, 2010) or sociocultural adaptation (Ward et al., 2009). Consequently, we hypothesize:

$\mathrm{H} 2 \mathrm{c}$ : Motivational CQ is positively related to adaptive selling behavior.

Behavioral CQ - the capability to exhibit appropriate verbal and nonverbal actions in crosscultural interactions - is likely to promote ASB in a international selling context. By exhibiting the appropriate actions, such as the words used during an interaction with a customer, the tone, the gestures, facial expressions and body language, ISEs are more likely to gain acceptance from potential customers, and develop interpersonal relationships (Ang et al., 2007; Lin et al., 2012). ISEs may have the cultural knowledge and the motivation to participate in cross-cultural context, but they could be ineffective in adapting their sales approach if they make behavioral mistakes when facing customers from other cultures (c.f. Haslberger et al., 2013). Formally, we posit:

$\mathrm{H} 2 \mathrm{~d}$ : Behavioral CQ is positively related to adaptive selling behavior.

The moderating effects of cultural distance and intrinsic motivation in the CQ-ASB relationship 
Ott and Michailova (2018) have expressed the need for research that considers contextual and individual differences as moderators in the relationship between CQ and adjustment, to comprehend its boundaries. This study explores cultural distance (a contextual difference) and intrinsic motivation (an individual difference) as moderators in the CQ-ASB relationship. Cultural distance. This concept refers to the differences between host and home countries in cultural aspects such as values, norms, beliefs, traditions, economic and political systems (Hofstede, 1980; Shao et al., 2020; Shenkar, 2001) and appears as a crucial variable to understand how difficult adaptation in some contexts could be.

Cultural distance has been explored as a moderator of the relationship between CQ and adjustment, mainly in the context of expatriate executives and related to general adjustment and/or work-related adjustment (Chen et al., 2010; Zhang, 2012). However, in the case of international B2B selling, there is no evidence of whether cultural distance affects the CQ-ASB relationship or not. This issue is critical to inform sales managers in supplier companies on how to assign sales executives to international customers.

Several authors have established that CQ is more relevant for adaptation when the cultural distance is larger (Kim et al., 2008; Pandey and Charoensukmongkol, 2019; Varela and GatlinWatts, 2014). In those situations, a salesperson with high CQ should better adapt to new situations, revising his/her preconceived notions, assimilating new ones, and behaving adequately (Varela and Gatlin-Watts, 2014). In countries that are culturally closer, he/she can apply strategies similar to those utilized in his/her home country and obtain good results, because it is easier to understand and anticipate customers' behaviors, making their CQ less relevant (Pandey and Charoensukmongkol, 2019). Based on this, we propose: 
H3: Cultural distance positively moderates the relationship between CQ and adaptive selling behavior.

Intrinsic motivation. In a sales context, people with high intrinsic motivation prefer rewards that are intrinsically appealing, such as pride, enjoyment and personal satisfaction, in contrast to those which leads to some external consequences (Román and Iacobucci, 2010). Previous research has found that intrinsic motivation positively influences adaptive selling (Bande et al., 2016; Jaramillo et al., 2007; Román and Iacobucci, 2010; Spiro and Weitz, 1990). Similarly, Kimura et al. (2019) found that intrinsic motivation helps salespeople to concentrate their general skills in reaching their goals, showing more adaptive behaviors.

Intrinsic motivation has also been associated with CQ. Holtbrugge and Engelhard (2015) showed that, while studying abroad, intrinsically motivated people tend to develop their CQ more than those extrinsically motivated. The desire for studying abroad and interacting with individuals from other cultures play an important role in adapting better and faster to the host country because intrinsically motivated people get involved more actively in learning about the host culture. Additionally, in the context of religious expatriates, Presbitero (2017) found that intrinsic motivation moderated the relationship between CQ and the individuals' psychological and sociocultural adaptation. Despite this evidence, intrinsic motivation has not been tested as a possible moderator in the CQ-ASB relationship. Therefore, we posit,

H4: Intrinsic motivation positively moderates the relationship between CQ and adaptive selling behavior. 


\section{Research methodology}

\section{Sample and data collection}

The target population for this study is defined as international sales executives (ISEs), and more precisely, international business travelers working in sales (Collings et al., 2007), who travel from their home country to serve their customers at a different country, for short periods of time.

The sample frame was obtained from a database of U.S. salespeople who served international customers. The identified potential respondents were contacted by e-mail and invited to complete an online survey. We obtained a sample of 310 ISEs (all U.S. Citizens), representing 32 different industries and traveling to 82 countries. They ranged in age from 18 to 75 (mean: 34.6 , s.d.: 13.04$)$, most of them were male (64.2\%, versus $35.8 \%$ female), and $82.6 \%$ had completed undergraduate or graduate studies.

The response rate for the survey was $36.9 \%$. We tested for the likelihood of non-response bias by following the extrapolation technique by Armstrong and Overton (1977). We split the total sample into two groups: participants who completed the survey before the second wave of invitations, and who did it after that. Using a t-test, we compared the mean responses on each variable; the results revealed no significant differences between the two groups, leading us to conclude that respondents did not differ from non-respondents.

We tested for common method variance (CMV) by conducting a Harman one-factor test (Podsakoff et al., 2003) with all the items of CQ, ASB, intrinsic motivation, ethnocentrism, and role ambiguity. It was found that the first factor accounted for $35.89 \%$ of the total variance; thus, common method bias does not seem to affect the validity of the results. In addition, following the reccomendations of Aaker et al. (2010) regarding questionnaire design, the categories in multiple 
scales were displayed in a random way, and the question order was pre-tested to prevent order bias.

\section{Control variables}

Based on previous literature, we included some control variables. Ethnocentrism is a tendency of people to see their own group as superior (Neuliep and McCroskey, 1997; Siamagka and Balabanis, 2015), and it is possible that executives who are highly ethnocentric will show lower levels of ASB. Role ambiguity has been shown to be negatively associated with ASB (Román and Iacobucci, 2010). International experience has been associated with higher levels of CQ (Engle and Crowne, 2014) and could be positively related to ASB. Finally, sales experience, age, and gender have also been studied as potential antecedents of ASB (Franke and Park, 2006; Levy and Sharma, 1994; Shoemaker and Johlke, 2002; Siguaw and Honeycutt, 1995).

\section{Measurement of the constructs}

Adaptive selling behavior was measured with the ADAPTS-SV 5-item, 7-point scale by Robinson et al. (2002). Cultural intelligence was measured using the CQS scale, a 20-item, 7Point scale by Van Dyne et al. (2008). Intrinsic motivation was measured using the 4-item scale by Román and Iacobucci (2010). Cultural distance was measured using the Kogut and Singh (1988) index, which is based on four of Hofstede's national culture dimensions (individualism, masculinity, power distance, and uncertainty avoidance). Ethnocentrism was measured using a 10-item, 5-point scale, adapted from the GENE scale (Neuliep and McCroskey, 1997). Role ambiguity was measured with the 4-item scale by Román and Iacobucci (2010). International experience was measured as the number of countries a salesperson has lived in and/or visited 
(Crowne, 2006; Engle and Crowne, 2014). Sales experience was measured by the total number of years working in sales (Levy and Sharma, 1994; Giacobbe et al., 2006). Age (specifically, year of birth) and gender were asked to participants directly in the survey.

Previous to testing the hypotheses, we checked the psychometric properties of the constructs and the adequacy of the measures. For each construct, we calculated Cronbach's alpha reliability indices: all of them were above the 0.7 threshold proposed by Nunnally and Bernstein (1994). In addition, all measures showed composite reliability values above the value of 0.7 recommended by Hair et al. (1998). A complete list of the scales used for the variables, the Cronbach's alphas, and the items' loadings are shown in Table 1.

Table 1 Measures for the constructs, coefficient alpha, and item loadings

$$
\text { INSERT TABLE } 1 \text { HERE }
$$

We then evaluated convergent and discriminant validity (Table 2). The constructs showed average variance extracted (AVE) values higher than 0.5 and composite reliability values higher than AVE, showing adequate convergent validity (Fornell and Larcker, 1981; Hair et al., 1998). Discriminant validity was evaluated comparing AVE with squared correlations between latent variables. We found that there is discriminant validity between every pair of constructs, except among CQ facets; however, these variables are conceptualized as expected to be correlated (Ang et al., 2007; Ward et al., 2009).

Table 2 Average variance extracted (AVE), composite reliability, and squared correlations 


\section{Model estimation}

To test the hypotheses, we conducted OLS multiple regression analysis, with ASB as the dependent variable. We ran four models: the first two with aggregate CQ and the moderator effects as independent variables, and the other two with the four facets of CQ (metacognitive, cognitive, motivational, and behavioral) and the moderator effects as independent variables. All models included the control variables. We used robust standard errors to correct for heteroscedasticity; all the other assumptions for OLS regression were also met.

\section{Results}

\section{Descriptive statistics}

Table 3 shows the mean and standard deviation for each variable and the correlations between every pair of variables. In the case of the correlations between gender (dichotomous variable) and the rest of variables (all continuous), we computed a point-biserial correlation, which is a special case of the Pearson correlation. We find that within the CQ facets, motivational CQ shows the highest mean, followed by metacognitive CQ, and behavioral CQ; cognitive CQ has the lowest mean and the highest standard deviation. As expected, we find that the facets of CQ are significantly correlated but distinct; the only exception is cognitive versus metacognitive CQ with a correlation of .81 .

Table 3 Means, standard deviations, and correlations 


\section{Hypotheses testing}

$C Q$ as an aggregate construct and moderating effects (models 1 and 2). Hypothesis 1, which anticipated a positive association between CQ and ASB, is supported before $(\beta=0.417$; $<$ $0.01)$ and after introducing moderators $(\beta=0.950 ; \mathrm{p}<0.01)$. Hypothesis 3 , which stated a moderating effect of cultural distance in the relationship between CQ and ASB is not supported $(\beta=-0.018 ; p>0.05)$. Finally, Hypothesis 4 , which stated a moderating effect of intrinsic motivation in the relationship between CQ and ASB is partially supported $(\beta=-0.081 ; \mathrm{p}<0.05)$. In fact, there is an effect, but in the opposite direction relative to our expectation.

Regarding the control variables, we find in both models the following to be significant predictors of ASB: ethnocentrism, international experience, and role ambiguity. In contrast, sales experience, age, and gender are not significant. Figure 2 shows the results for model 2.

Figure 2: Results for regression model 2

\section{INSERT FIGURE 2 HERE}

$C Q$ in its facets and moderating effects (models 3 and 4 ). In this case, due to having more complex models (facets and eight interaction effects), we controlled for multicollinearity, following the procedure described by Balli and Sørensen (2013).

Hypothesis 2a, which anticipated a positive association between cognitive CQ and ASB, is not supported (Model 3: $\beta=-0.047 ; p>0.05 ;$ Model 4: $\beta=-0.039 ; p>0.05$ ). Hypothesis $2 b$, which suggested a positive relationship between metacognitive CQ and ASB, is supported before $(\beta=0.183 ; \mathrm{p}<0.05)$ and after introducing moderators $(\beta=0.167 ; \mathrm{p}<0.05)$. Hypothesis $2 \mathrm{c}$, which predicted a positive association between motivational CQ and ASB, is supported (Model 
3: $\beta=0.150 ; p<0.05 ;$ Model 4: $\beta=0.143 ; p<0.05)$. Finally, hypothesis $2 d$, which expected a positive association between behavioral CQ and ASB, is also supported (Model 3: $\beta=0.150 ; \mathrm{p}<$ 0.05; Model 4: $\beta=0.154 ; \mathrm{p}<0.05)$.

Regarding the moderating effects, hypotheses 3 and 4 are not supported by model 4, which is not consistent with model 2. A possible explanation is that the presence of 20 regressors (model 4) instead of 11 (model 2) decreases too much the ratio sample size to regressors, and makes the moderating effects become not significant (Sekaran and Bougie, 2016).

With respect to control variables, we find ethnocentrism, role ambiguity, and international experience to be significantly associated with ASB, while sales experience, age, and gender are not. Figure 3 shows the results for model 4.

Figure 3: Results for regression model 4

$$
\text { INSERT FIGURE } 3 \text { HERE }
$$

Table 4 shows the results of the regression analysis for the four models.

Table 4 Regression models: Antecedents of adaptive selling behavior

INSERT TABLE 4 HERE

\section{Discussion}

\section{Theoretical contribution}


This research contributes to the literature on sales management in an increasingly crucial topic international business-to-business relationships (Jukka et al., 2017) - while responding to a call for conceptual development on the role of culture in individual encounters (Ivanova-Gongne, 2015). We extent existing knowledge on the antecedents of ASB, a key predictor of sales performance, by examining the role of cultural intelligence (CQ) as a critical competence for international sales executives. Salespeople increasingly face the challenge of dealing with customers from different cultures; however, supplier companies rarely consider cultural competencies such as CQ when hiring or training international sales executives. Based on this research, sales managers should be encouraged to assess the CQ of candidates to or executives in international sales positions to increase ASB by making the right decisions on salespeople's hiring, allocation to customers and markets, and training, among other applications of CQ assessments.

This study also extends existing research on CQ by showing its relevance on a different context relative to the dominant one, which so far has mostly been the cultural adjustment of expatriates. We focus on a specific category of cross-cultural salesperson, which is the international business traveler (IBT) for short periods of time; this represents a very unexplored context in CQ research in spite of its practical relevance. International business travelers in sales positions are commonly engaged in relationships with customers from different countries, and thus having country-specific cultural knowledge becomes less useful (Earley \& Peterson, 2004). We build on the work by Hansen et al. (2011), which highlights the potential relevance of CQ as a driver of cultural adaptation in selling but does not test empirically how CQ and its facets may influence ASB or under which conditions this could be more relevant. A major finding of our study is that CQ, as an aggregate construct, is positively related to ASB in international selling, 
which advances our knowledge on the antecedents of ASB in a cross-cultural context. Therefore, this research provides additional evidence of the importance of CQ generally, and specifically in the context of IBTs in sales positions.

A third contribution relates to understanding the importance of the facets of CQ. Specifically, we find metacognitive CQ to be the most important predictor of ASB, followed by motivational CQ and behavioral CQ. Contrary to our expectations, cognitive CQ does not appear to have a statistically significant relationship with ASB. The latter may be explained, at least in part, by how selling is done, and the profile of ISEs. It might be that ISEs, compared to expatriates and immigrants - which have been the unit of analysis in most of previous research vary less in their cognitive CQ scores. ISEs may have relatively similar job demands that are less likely to extend to the whole complexity of living and working in a country for a long time (Baruch et al., 2013). This result challenges the underlying assumptions around cultural intelligence in that all facets are important for the success of globally mobile workers and, therefore, supports the idea that cultural adjustment research needs to factor in the different dimensions of adjustment, as well as the roles and job profiles of international executives (Haslberger et al., 2013). Notwithstanding, as we have only looked at CQ of ISEs, these potential longer-term adjustment implications remain as speculations. As mentioned before, metacognitive CQ does predict adaptive selling behavior; this suggests that the way salespeople use cultural knowledge is more important than the cultural knowledge itself. In addition, motivational CQ and behavioral CQ appear to be very relevant predictors of ASB.

In contrast to previous research, our results show that cultural distance does not play a significant role in the relationship between CQ and ASB. Given the task similarity explored above, it might be that the cultural distances described in culture studies (e.g. Hofstede, 1980) 
are simply too broad in capturing the nuances of the specific context (McSweeney, 2002).

Nevertheless, intrinsic motivation does play an important moderating role in this context. When intrinsic motivation is high, the strength of the CQ-ASB relationship is reduced, which indicates that intrinsic motivation helps salespeople compensate a low CQ in order to adapt the selling approach.

\section{Managerial implications}

The findings of this research suggest that supplier companies involved in international selling should consider the cultural intelligence of their salespeople, for selection, training, and coaching. As a multidimensional competence, with cognitive, motivational and behavioral components, CQ becomes actionable from both a didactic (provision of factual information) and an experiential (learning how to learn) perspective (Reiche et al., 2015).

First, it is advisable to factor CQ into the selection for international sales positions. Candidates with higher CQ levels should adapt more effectively to customers' needs and contexts, and consequently perform better. In this sense, candidates may be asked to complete a questionnaire with the CQ scales developed by Van Dyne et al. (2008) or CQ facets could be included as part of stages of an assessment center in the selection process, such as interviews, role-plays, simulations, or group discussions. For example, a simulation exercise could be to present sales executives a set of cultural situations when visiting an international customer, to then assess the executives' perceptions and reactions, and the extent to which they would adapt the selling approach.

Furthermore, the four facets of CQ should be considered relevant components of ISE training programs as these elements can be developed (Johnson et al., 2006). These facets may or 
may not be correlated; therefore, some salespeople may have high levels of some CQ dimensions, but require some training to increase the levels of other ones. For instance, given that adequate behavior lies at the heart of cross-cultural interaction, behavioral CQ is highly important to build rapport and to construct and maintain a successful relationship (Nickels et al., 1983; Simintiras and Thomas, 1998). Thus, some ISEs may require training in behavior-shaping techniques (Luthans and Kreitner, 1985), for example, through role-playing on cultural dynamics to learn what to expect and how to behave in sales meetings. Likewise, ISEs could be trained using self-learning videos that showcase social norms and people's behavior in different situations of interpersonal interaction.

Since motivational CQ is a relevant determinant of adaptive behavior, supplier companies involved in international selling should proactively seek that aspect in their selection processes, and develop training programs that encourage the motivation to interact across cultures. Earley and Peterson (2004) propose some guidelines to increase motivational CQ through training programs training programs that develop self-efficacy in interacting with people from other cultures. In this respect, ISEs could be exposed to a series of intercultural interactions in a controlled classroom setting, starting with short and simple tasks; as they build confidence, greater complexity coud be added until an adequate level of self-efficacy is achieved.

Finally, high levels of metacognitive CQ are likely to increase adaptive selling behavior. Therefore, ISEs' cross-cultural training should challenge the participants' cultural assumptions and mental models (Ang and Van Dyne, 2008; Dickmann and Baruch, 2011) and experiment with nationally diverse management actions and mindsets (Hamlin et al., 2006). Such initiatives should foster metacognitive CQ, and may be implemented in workshops, where ISEs are 
exposed to diverse cultural settings that characterize some of the customers' countries of origin, to then apply and adjust their cultural knowledge.

\section{Limitations and future research}

This research has some limitations. First, the study includes only a sample of US-based international salespeople working in the B2B context, which limits the generalizability of the findings to salespeople from other countries or in other contexts. Second, although our model controls for several variables that have been found in previous research to be related to ASB, there are some other possible antecedents related to cognitive styles (e.g. intuiting versus sensing, or thinking versus feeling) or to competences and traits (e.g. interaction involvement, or communication apprehension) that we were not able to include in this study.

One fruitful area for future research would be to investigate CQ of ISEs from other regions of the world, such as Europe, Asia, or Latin America. It could be that cognitive CQ becomes a significant predictor of ASB, or cultural distance has a significant moderating role in the CQASB relationship, in countries from different regions of the world. Another venue for further research would be to look, in the same model, at the influence of CQ on sales performance through ASB, to explore whether the positive ASB-performance relationship, that has been well established in the literature, is reduced or not when CQ directly influences sales performance. Finally, future research could study other cross-cultural competences as antecedents of ASB, such as cultural agility or global mindset. 


\section{References}

Aaker, D. A., Kumar, V., Day, G. S. and Leone, R. (2009). Marketing Research (7th ed.), John Wiley and Sons, New York, NY.

Adair, W. L., Hideg, I., and Spence, J. R. (2013), “The culturally intelligent team: The impact of team cultural intelligence and cultural heterogeneity on team shared values", Journal of Cross-Cultural Psychology, Vol. 44 No. 6, pp. 941-962.

https://doi.org/10.1177/0022022113492894

Alnakhli, H., Singh, R., Agnihotri, R. and Itani, O. S. (2020), "From cognition to action: the effect of thought self-leadership strategies and self-monitoring on adaptive selling behavior", Journal of Business \& Industrial Marketing, Vol. 35 No. 12, pp. 1915-1927. https://doi.org/10.1108/JBIM-06-2019-0302

Ang, S. and Van Dyne, L.(2008), Conceptualization of cultural intelligence: Definition, distinctiveness, and nomological network. In S. Ang, \& L. Van Dyne (Eds.), Handbook of Cultural Intelligence: Theory, Measurement, and Applications, Routledge, Abingdon, UK, pp. 3-15.

Ang, S., Van Dyne, L., Koh, C., Ng, K. Y., Templer, K. J., Tay, C. and Chandrasekar, N. A. (2007), "Cultural intelligence: Its measurement and effects on cultural judgment and decision making, cultural adaptation and task performance", Management and Organization Review, Vol. 3 No. 3, pp. 335-371. https://doi.org/10.1111/j.1740-8784.2007.00082.x

Armstrong, J. S. and Overton, T. S. (1977), "Estimating nonresponse bias in mail surveys", Journal of Marketing Research, Vol. 14 No. 3, pp. 396-402. https://doi.org/10.1177/002224377701400320 
Balli, H. O. and Sørensen, B. E. (2013), "Interaction effects in econometrics", Empirical Economics, Vol. 45 No. 1, pp. 583-603. https://doi.org/10.1007/s00181-012-0604-2

Bandura, A. (1999), A social cognitive theory of personality. In Handbook of Personality $2^{\text {nd }}$ ed., Guilford, New York, NY, pp. 154-196.

Bande, B., Fernández-Ferrín, P., Varela-Neira, C. and Otero-Neira, C. (2016), "Exploring the relationship among servant leadership, intrinsic motivation and performance in an industrial sales setting”, Journal of Business \& Industrial Marketing, Vol. 31 No. 2, pp. 219-231. https://doi.org/10.1108/JBIM-03-2014-0046

Bartel-Radic, A. and Giannelloni, J. L. (2017), “A renewed perspective on the measurement of cross-cultural competence: An approach through personality traits and cross-cultural knowledge", European Management Journal, Vol. 35 No. 5, pp. 632-644.

Baruch, Y., Dickmann, M., Altman, Y. and Bournois, F. (2013), "Exploring international work: Types and dimensions of global careers", The International Journal of Human Resource Management, Vol. 24 No. 12, pp. 2369-2393. https://doi.org/10.1080/09585192.2013.781435

Boorom, M. L., Goolsby, J. R. and Ramsey, R. P. (1998), "Relational communication traits and their effect on adaptiveness and sales performance", Journal of the Academy of Marketing Science, Vol. 26 No. 1, pp. 16-30. https://doi.org/10.1177/0092070398261003

Brett, J. M. (2017), “Culture and negotiation strategy”, Journal of Business \& Industrial Marketing, Vol. 34 No. 4, pp. 587-590. https://doi.org/10.1108/JBIM-11-2015-0230

Brislin, R., Worthley, R. and Macnab, B. (2006), “Cultural intelligence: Understanding behaviors that serve people's goals", Group \& Organization Management, Vol. 31 No. 1, pp. 40-55. https://doi.org/10.1177/1059601105275262

Cartus (2012), Trends in Global Relocations-report. Cartus, Dandury, CA. 
Chakrabarty, S., Brown, G. and Widing, R. E. (2010), "Closed influence tactics: do smugglers win in the long run?", Journal of Personal Selling \& Sales Management, Vol. 30 No. 1, pp. 23-32. https://doi.org/10.2753/PSS0885-3134300102

Chakrabarty, S., Brown, G., Widing, R. E. and Taylor, R. D. (2004), “Analysis and recommendations for the alternative measures of adaptive selling", Journal of Personal Selling \& Sales Management, Vol. 24 No. 2, pp. 125-133.

https://doi.org/10.1080/08853134.2004.10749024

Charoensukmongkol, P. (2020), “The efficacy of cultural intelligence for adaptive selling behaviors in cross-cultural selling: The moderating effect of trait mindfulness", Journal of Global Marketing, Vol. 33 No. 3, pp. 141-157. https://doi.org/10.1080/08911762.2019.1654586

Chen, G., Kirkman, B. L., Kim, K., Farh, C. I. C. and Tangirala S. (2010), "When does crosscultural motivation enhance expatriate effectiveness? A multilevel investigation of the moderating roles of subsidiary support and cultural distance. Academy of Management Journal, Vol. 53 No. 5, pp. 1110-1130. https//doi.org/10.5465/amj.2010.54533217

Chen, X. P., Liu, D. and Portnoy, R. (2012), “A multilevel investigation of motivational cultural intelligence, organizational diversity climate, and cultural sales: Evidence from US real estate firms”, Journal of Applied Psychology, Vol. 97 No. 1, pp. 93-106. http://dx.doi.org/10.1037/a0024697

Chua, R. Y., Morris, M. W. and Mor, S. (2012), “Collaborating across cultures: Cultural metacognition and affect-based trust in creative collaboration", Organizational Behavior and Human Decision Processes, Vol. 118 No. 2, pp. 116-131.

https://doi.org/10.1016/j.obhdp.2012.03.009 
Collings, D. G., Scullion, H. and Morley, M. J. (2007), "Changing patterns of global staffing in the multinational enterprise: Challenges to the conventional expatriate assignment and emerging alternatives”, Journal of World Business, Vol. 42 No. 2, pp. 198-213. https://doi.org/10.1016/j.jwb.2007.02.005

Crowne, K. A. (2006), Examining the antecedents of cultural intelligence. In Widener University Proceedings-AIB-SE (USA) Annual Meeting (pp. 127-138), Clearwater Beach, Fl.

Delpechitre, D. and Baker, D. S. (2017), “Cross-cultural selling: Examining the importance of cultural intelligence in sales education", Journal of Marketing Education, Vol. 39 No. 2, pp. 94-108. https://doi.org/10.1177/0273475317710060

Dickmann, M. and Baruch, Y. (2011), Global Careers, Routledge, New York, NY.

Dion, P. A., Easterling, D. and Javalgi, R. (1997), "Women in the business-to-business salesforce: Some differences in performance factors", Industrial Marketing Management, Vol. 26 No. 5, pp. 447-457. https://doi.org/10.1016/S0019-8501(96)00152-6

Earley, P. C. (2002), "Redefining interactions across cultures and organizations: Moving forward with cultural intelligence”, Research in Organizational Behavior, Vol. 24, pp. 271-299. https://doi.org/10.1016/S0191-3085(02)24008-3

Earley, P. C. and Ang, S. (2003), Cultural Intelligence: Individual Interactions Across Cultures, Stanford University Press, Palo Alto, CA.

Earley, P. C. and Mosakowski, E. (2004), “Cultural intelligence”, Harvard Business Review, Vol. 82 No. 10, pp. 139-146.

Earley, P. C. and Peterson, R. S. (2004), “The elusive cultural chameleon: Cultural intelligence as a new approach to intercultural training for the global manager", Academy of Management 
Learning \& Education, Vol. 3 No. 1, pp. 100-115.

https://doi.org/10.5465/amle.2004.12436826

Elo, M., Benjowsky, C. and Nummela, N. (2015), "Intercultural competences and interaction schemes - Four forces regulating dyadic encounters in international business", Industrial Marketing Management, Vol. 48, pp. 38-49. https://doi.org/10.1016/j.indmarman.2015.03.007

Engle, R. L. and Crowne, K. A. (2014), “The impact of international experience on cultural intelligence: an application of contact theory in a structured short-term programme", Human Resource Development International, Vol. 17 No. 1, pp. 30-46. https://doi.org/10.1080/13678868.2013.856206

Eppler, D. B., Honeycutt, E. D., Ford, J. B. and Markowski, E. P. (1998), “The relationship of self-monitoring and adaptiveness to the performance of real estate sales professionals", The Journal of Business and Economic Studies, Vol. 4 No. 2, pp. 37-51.

Fornell, C. and Larcker, D. F. (1981), "Evaluating structural equation models with unobservable variables and measurement error", Journal of Marketing Research, Vol. 18 No. 1, pp. 39-50. https://doi.org/10.1177/002224378101800104

Franke, G. R. and Park, J. E. (2006), “Salesperson adaptive selling behavior and customer orientation: A meta-analysis", Journal of Marketing Research, Vol. 43 No. 4, pp. 693-702. https://doi.org/10.1509/jmkr.43.4.693

Giacobbe, R. W., Jackson Jr, D. W., Crosby, L. A. and Bridges, C. M. (2006), “A contingency approach to adaptive selling behavior and sales performance: Selling situations and salesperson characteristics”, Journal of Personal Selling \& Sales Management, Vol. 26 No. 2, pp. 115-142. https://doi.org/10.2753/PSS0885-3134260202 
Hair, J. F., Anderson, R. E., Tatham, R. L. and Black, W. C. (1998), Multivariate Data Analysis (Vol. 5, No. 3, pp. 207-219). Prentice Hall, Upper Saddle River, NJ.

Hamlin, R. G., Ellinger, A. D. and Beattie, R. S. (2006), "Coaching at the heart of managerial effectiveness: A cross-cultural study of managerial behaviours", Human Resource Development International, Vol. 9 No. 3, pp. 305-331. https://doi.org/10.1080/13678860600893524

Hansen, J. D., Singh, T., Weilbaker, D. C. and Guesalaga, R. (2011), “Cultural intelligence in cross-cultural selling: propositions and directions for future research", Journal of Personal Selling \& Sales Management, Vol. 31 No. 3, pp. 243-254. https://doi.org/10.2753/PSS08853134310303

Harindranath, R. M., Sivakumaran, B. and Jacob, J. (2019), “The moderating role of sales experience in adaptive selling, customer orientation and job satisfaction in a unionized setting”, Journal of Business \& Industrial Marketing, Vol. 34 No. 8, pp. 1724-1735. https://doi.org/10.1108/JBIM-08-2018-0233

Haslberger, A., Brewster, C. and Hippler, T. (2013), "The dimensions of expatriate adjustment”, Human Resource Management, Vol. 52 No. 3, pp. 333-351. https://doi.org/10.1002/hrm.21531

Haslberger, A. and Vaiman, V. (2013), Self-initiated expatriates: A neglected source of the global talent flow. In V. Vaiman and A. Haslberger (Eds.), Talent Management of Selfinitiated Expatriates (pp. 1-15), Palgrave MacMillan, London, UK.

Hofstede, G. (1980), Culture's Consequences, Sage Publications, Beverly Hills, CA.

Holtbrugge, D. and Engelhard, F. (2015), “Study abroad programs: Individual motivations, cultural intelligence, and the mediating role of cultural boundary spanning", Academy of 
Management Learning \& Education, Vol. 15 No. 3, pp. 435-455.

https://doi.org/10.5465/amle.2015.0128

Imai, L. and Gelfand, M. J. (2010), "The culturally intelligent negotiator: The impact of cultural intelligence (CQ) on negotiation sequences and outcomes", Organizational Behavior and Human Decision Processes, Vol. 112 No. 2, pp. 83-98.

https://doi.org/10.1016/j.obhdp.2010.02.001

Ivanova-Gongne, M. (2015), “Culture in business relationship interaction: an individual perspective”, Journal of Business \& Industrial Marketing, Vol. 30 No. 5, pp. 608-615. https://doi.org/10.1108/JBIM-01-2013-0002

Ivanova-Gongne, M., and Torkkeli, L. (2018), "No manager is an island: culture in sensemaking of business networking”, Journal of Business \& Industrial Marketing, Vol. 33 No. 5, pp. 638650. https://doi.org/10.1108/JBIM-07-2016-0154

Jaramillo, F., Locander, W. B., Spector, P. E. and Harris, E. G. (2007), "Getting the job done: The moderating role of initiative on the relationship between intrinsic motivation and adaptive selling”, Journal of Personal Selling \& Sales Management, Vol. 27 No. 1, pp. 59-74. https://doi.org/10.2753/PSS0885-3134270104

Johnson, J. P., Lenartowicz, T. and Apud, S. (2006), “Cross-cultural competence in international business: Toward a definition and a model", Journal of International Business Studies, Vol. 37 No. 4, pp. 525-543. https://doi.org/10.1057/palgrave.jibs.8400205

Jukka, M., Andreeva, T., Blomqvist, K., and Puumalainen, K. (2017), “A cross-cultural perspective on relational exchange", Journal of Business \& Industrial Marketing, Vol. 32 No. 7, pp. 937-950. https://doi.org/10.1108/JBIM-03-2016-0048 
Kim, K., Kirkman, B. L. and Chen, G. (2008), Cultural intelligence and international assignment effectiveness: A conceptual model and preliminary findings. In S. Ang and L. Van Dyne (Eds.), Handbook of Cultural Intelligence: Theory, Measurement, and Applications, Routledge, Abingdon, UK, pp 71-90.

Kimura, T., Bande, B. and Fernández-Ferrín, P. (2019), "The roles of political skill and intrinsic motivation in performance prediction of adaptive selling", Industrial Marketing Management, Vol. 77, pp. 198-208. https://doi.org/10.1016/j.indmarman.2018.09.005

Kogut, B. and Singh, H. (1988), "The effect of national culture on the choice of entry mode", Journal of International Business Studies, Vol. 19 No. 3, pp. 411-432. https://doi.org/10.1057/palgrave.jibs.8490394

Lambert, B. W., Ohai, T. and Kerkhoff, E. M. (2009), World-class Selling: New Sales Competencies, American Society for Training \& Development, Alexandria, VA.

Lee, L. Y. and Sukoco, B. M. (2010), “The effects of cultural intelligence on expatriate performance: The moderating effects of international experience", The International Journal of Human Resource Management, Vol. 21 No. 7, pp. 963-981. https://doi.org/10.1080/09585191003783397

Levy, M. and Sharma, A. (1994), “Adaptive selling: the role of gender, age, sales experience, and education”, Journal of Business Research, Vol. 31 No. 1, pp. 39-47. https://doi.org/10.1016/0148-2963(94)90044-2

Limbu, Y. B., Jayachandran, C., Babin, B. J. and Peterson, R. T. (2016), "Empathy, nonverbal immediacy, and salesperson performance: the mediating role of adaptive selling behavior", Journal of Business \& Industrial Marketing. Vol. 31 No. 5, pp. 654-667.

https://doi.org/10.1108/JBIM-03-2015-0048 
Lin, Y. C., Chen, A. S. Y. and Song, Y. C. (2012), "Does your intelligence help to survive in a foreign jungle? The effects of cultural intelligence and emotional intelligence on crosscultural adjustment", International Journal of Intercultural Relations, Vol. 36 No. 4, pp. 541552. https://doi.org/10.1016/j.ijintrel.2012.03.001

Luthans, F. and Kreitner, R. (1985), Organizational Behaviour Modification and Beyond: An Operant and Social Learning Approach, Scott Foresman \& Co., Glenview, IL.

Magnusson, P., Westjohn, S. A., Semenov, A. V., Randrianasolo, A. A. and Zdravkovic, S. (2013), "The role of cultural intelligence in marketing adaptation and export performance", Journal of International Marketing, Vol. 21 No. 4, pp. 44-61. https://doi.org/10.1509/jim.13.0055

Malek, M. A. and Budhwar, P. (2013), "Cultural intelligence as a predictor of expatriate adjustment and performance in Malaysia”, Journal of World Business, Vol. 48 No. 2, pp. 222231. https://doi.org/10.1016/j.jwb.2012.07.006

McSweeney, B. (2002), "Hofstede's model of national cultural differences and their consequences: A triumph of faith-a failure of analysis”, Human Relations, Vol. 55 No. 1, pp. 89-118.

Murphy, W. H., Gölgeci, I. and Johnston, D. A. (2020), "Power-based behaviors between supply chain partners of diverse national and organizational cultures: The crucial role of boundary spanners' cultural intelligence", Journal of Business \& Industrial Marketing, Vol. 35 No. 2, pp. 204-218. https://doi.org/10.1108/JBIM-05-2018-0179

Neuliep, J. W. and McCroskey, J. C. (1997), “The development of a US and generalized ethnocentrism scale”, Communication Research Reports, Vol. 14 No. 4, pp. 385-398. https://doi.org/10.1080/08824099709388682 
Ng, K. Y., Van Dyne, L. and Ang, S. (2009), "From experience to experiential learning: Cultural intelligence as a learning capability for global leader development", Academy of Management Learning \& Education, Vol. 8 No. 4, pp. 511-526. https://doi.org/10.5465/amle.8.4.zqr511

Nickels, W. G., Everett, R. F. and Klein, R. (1983), "Rapport building for salespeople: A neurolinguistic approach”, Journal of Personal Selling \& Sales Management, Vol. 3 No. 2, pp. 1-7. https://doi.org/10.1080/08853134.1983.10754353

Nunnally, J. C. and Bernstein, I. H. (1994), Psychometric Theory, McGraw-Hill, New York, NY.

Ott, D. L. and Michailova, S. (2018), “Cultural intelligence: A review and new research avenues", International Journal of Management Reviews, Vol. 20 No. 1, pp. 99-119. https://doi.org/10.1111/ijmr.12118

Panagopoulos, N. G., Lee, N., Pullins, E. B., Avlonitis, G. J., Brassier, P., Guenzi, P., Humenberger, A., Kwiatek, P., Loe, T. W., Oksanen-Ylikoski, E., Peterson, R. M., Rogers, B. and Weilbaker, D. C. (2011), "Internationalizing sales research: Current status, opportunities, and challenges", Journal of Personal Selling \& Sales Management, Vol. 31 No. 3, pp. 219242. https://doi.org/10.2753/PSS0885-3134310302

Pandey, A. and Charoensukmongkol, P. (2019), "Contribution of cultural intelligence to adaptive selling and customer-oriented selling of salespeople at international trade shows: Does cultural similarity matter?", Journal of Asia Business Studies, Vol. 13 No. 1, pp. 79-96. https://doi.org/10.1108/JABS-08-2017-0138

Park, J. E. and Holloway, B. B. (2003), “Adaptive selling behavior revisited: An empirical examination of learning orientation, sales performance, and job satisfaction”, Journal of Personal Selling \& Sales Management, Vol. 23 No. 3, pp. 239-251.

https://doi.org/10.1080/08853134.2003.10749001 
Ployhart, R. E. and Weekley, J. A. (2015), Recruitment and selection in global organizations. In D. G. Collings, G. T. Wood, \& P. M. Caligiuri (Eds.), The Routledge Companion to International Human Resource Management (pp. 155-171), Routledge, New York, NY.

Podsakoff, P. M., MacKenzie, S. B., Lee, J. Y. and Podsakoff, N. P. (2003), "Common method biases in behavioral research: A critical review of the literature and recommended remedies", Journal of Applied Psychology, Vol. 88 No. 5, pp. 879-903. http://dx.doi.org/10.1037/00219010.88.5.879

Pornpitakpan, C. (2003), “Cultural adaptation and business relationships: Americans selling to Indonesians, Malaysians, and People's Republic of China Chinese”, Journal of Global Marketing, Vol. 16 No. 3, pp. 75-103. https://doi.org/10.1300/J042v16n03_05

Presbitero, A. (2017), "Religious expatriates' cultural intelligence and adaptation: The role of intrinsic motivation for successful expatriation”, Journal of Global Mobility: The Home of Expatriate Management Research, Vol. 5 No. 2, pp. 146-157.

Reiche, B. S., Lee, Y. T. and Quintanilla, J. (2015), Cross-cultural training and support practices of international assignees. In D. G. Collings, G. T. Wood, \& P. M. Caligiuri (Eds.), The Routledge Companion to International Human Resource Management, Routledge, New York, NY, pp 308-323.

Robinson Jr, L., Marshall, G. W., Moncrief, W. C. and Lassk, F. G. (2002), “Toward a shortened measure of adaptive selling”, Journal of Personal Selling \& Sales Management, Vol. 22 No. 2, pp. 111-118. https://doi.org/10.1080/08853134.2002.10754299

Román, S. and Iacobucci, D. (2010), “Antecedents and consequences of adaptive selling confidence and behavior: a dyadic analysis of salespeople and their customers", Journal of the 
Academy of Marketing Science, Vol. 38 No. 3, pp. 363-382. https://doi.org/10.1007/s11747009-0166-9

Schrock, W. A., Zhao, Y., Richards, K. A., Hughes, D. E., and Amin, M. S. (2018), “On the nature of international sales and sales management research: a social network-analytic perspective”, Journal of Personal Selling \& Sales Management, Vol. 38 No. 1, pp. 56-77.

Sekaran, U. and Bougie, R. (2016), Research Methods for Business: A Skill Building Approach, John Wiley \& Sons, West Sussex, UK.

Shao, L. H., Bouzdine-Chameeva, T. and Lunardo, R. (2020), "The interacting effect of business and cultural distances on relationship management and export performance: the case of wine export between France and China", Journal of Business \& Industrial Marketing, Vol. 32 No. 11, pp. 1659-1672. https://doi.org/10.1108/JBIM-04-2019-0142

Shenkar, O. (2001), "Cultural distance revisited: Towards a more rigorous conceptualization and measurement of cultural differences", Journal of International Business Studies, Vol. 32 No. 3, pp. 519-535. https://doi.org/10.1057/palgrave.jibs.8490982

Shoemaker, M. E. and Johlke, M. C. (2002), “An examination of the antecedents of a crucial selling skill: asking questions", Journal of Managerial Issues, pp. 118-131.

Siamagka, N. T. and Balabanis, G. (2015), "Revisiting consumer ethnocentrism: review, reconceptualization, and empirical testing”, Journal of International Marketing, Vol. 23 No. 3, pp. 66-86. https://doi.org/10.1509/jim.14.0085

Siguaw, J. A. and Honeycutt Jr, E. D. (1995), “An examination of gender differences in selling behaviors and job attitudes”, Industrial Marketing Management, Vol. 24 No. 1, pp. 45-52. https://doi.org/10.1016/0019-8501(94)00030-Z 
Simintiras, A. C., Ifie, K., Watkins, A. and Georgakas, K. (2013), “Antecedents of adaptive selling among retail salespeople: A multilevel analysis", Journal of Retailing and Consumer Services, Vol. 20 No. 4, pp. 419-428. https://doi.org/10.1016/j.jretconser.2013.04.004

Simintiras, A. C. and Thomas, A. H. (1998), "Cross-cultural sales negotiations: A literature review and research propositions", International Marketing Review, Vol. 15 No. 1, pp. 10-28. https://doi.org/10.1108/EUM0000000004481

Singh, R., Kumar, N. and Puri, S. (2017), “Thought self-leadership strategies and sales performance: integrating selling skills and adaptive selling behavior as missing links", Journal of Business \& Industrial Marketing, Vol. 32 No. 5, pp. 652-663. https://doi.org/10.1108/JBIM-06-2016-0127

Spiro, R. L. and Weitz, B. A. (1990), “Adaptive selling: Conceptualization, measurement, and nomological validity”, Journal of Marketing Research, Vol. 27 No. 1, pp. 61-69. http://dx.doi.org/10.2307/3172551

Templer, K. J., Tay, C. and Chandrasekar, N. A. (2006), "Motivational cultural intelligence, realistic job preview, realistic living conditions preview, and cross-cultural adjustment", Group \& Organization Management, Vol. 31 No. 1, pp. 154-173. https://doi.org/10.1177/1059601105275293

Triandis, H. C. (2006), “Cultural intelligence in organizations”, Group \& Organization Management, Vol. 31 No. 1, pp. 20-26. https://doi.org/10.1177/1059601105275253 Van Dyne, L., Ang, S. and Koh, C. (2008), Development and validation of the CQS: The Cultural Intelligence Scale. In S. Ang, \& L. Van Dyne (Eds.), Handbook of Cultural Intelligence, Routledge, Abingdon, UK, pp. 16-40. 
Van Dyne, L., Ang, S. and Koh, C. (2009), Cultural intelligence: Measurement and scale development. In M. A. Moodian (Ed.), Contemporary Leadership and Intercultural Competence: Exploring the Cross-cultural Dynamics Within Organizations, Sage, Thousand Oaks, CA, pp. 233-254.

Ward, C., Fischer, R., Zaid Lam, F. S. and Hall, L. (2009), “The convergent, discriminant, and incremental validity of scores on a self-report measure of cultural intelligence", Educational and Psychological Measurement, Vol. 69 No. 1, pp. 85-105.

https://doi.org/10.1177/0013164408322001

Weitz, B. A. (1981), "Effectiveness in sales interactions: A contingency framework", Journal of Marketing, Vol. 45 No. 1, pp. 85-103. https://doi.org/10.1177/002224298104500109

Weitz, B. A., Sujan, H. and Sujan, M. (1986), "Knowledge, motivation, and adaptive behavior: A framework for improving selling effectiveness", Journal of Marketing, Vol. 50 No. 4, pp. 174-191. https://doi.org/10.1177/002224298605000404

Wiseman, R. L., Hammer, M. R. and Nishida, H. (1989), "Predictors of intercultural communication competence", International Journal of Intercultural Relations, Vol. 13 No. 3, pp. 349-370. https://doi.org/10.1016/0147-1767(89)90017-5

Zhang, Y. (2012), "Expatriate development for cross-cultural adjustment: Effects of cultural distance and cultural intelligence”, Human Resource Development Review, Vol. 12 No. 2, pp. 177-199. https//doi.org/ 10.1177/1534484312461637 
Figure 1 Conceptual model

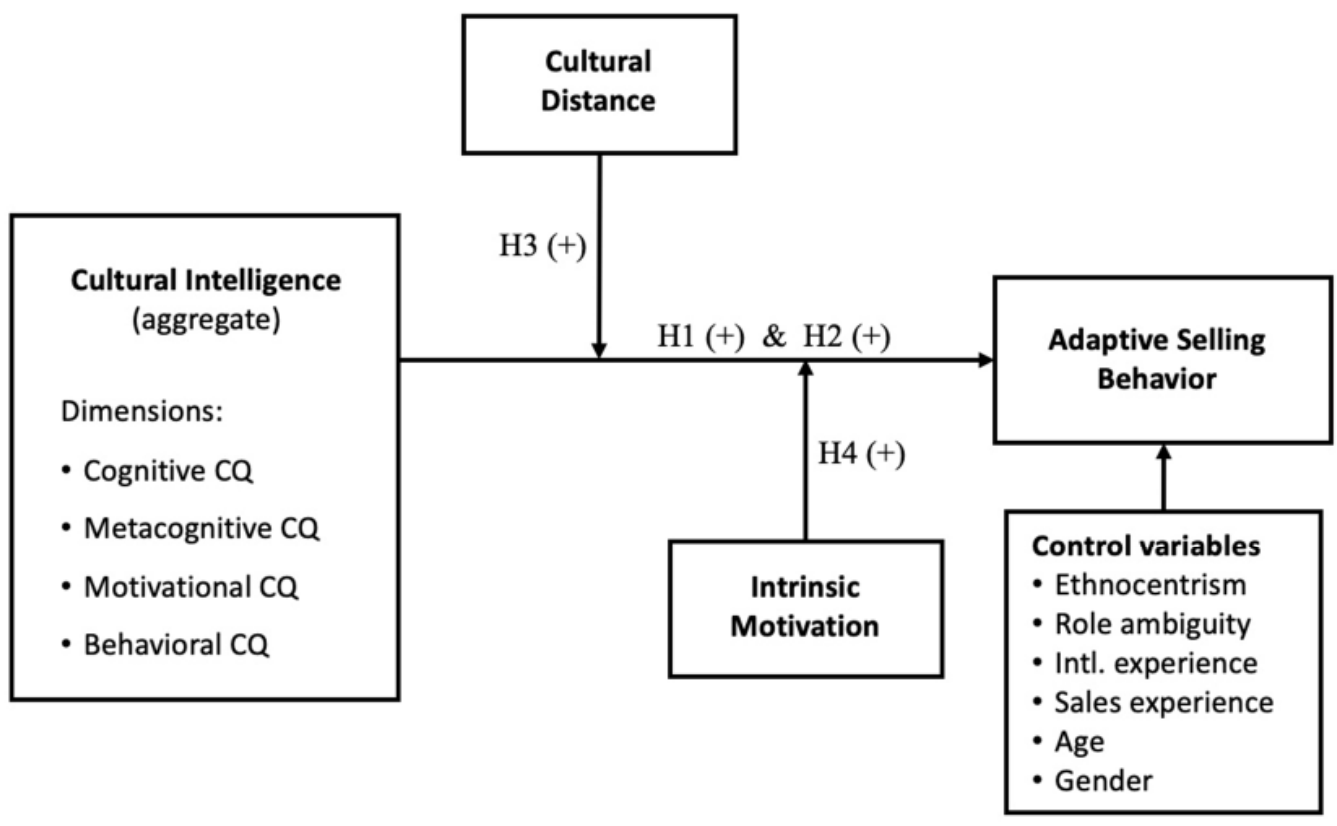


Table 1 Measures for the constructs, coefficient alpha, and item loadings

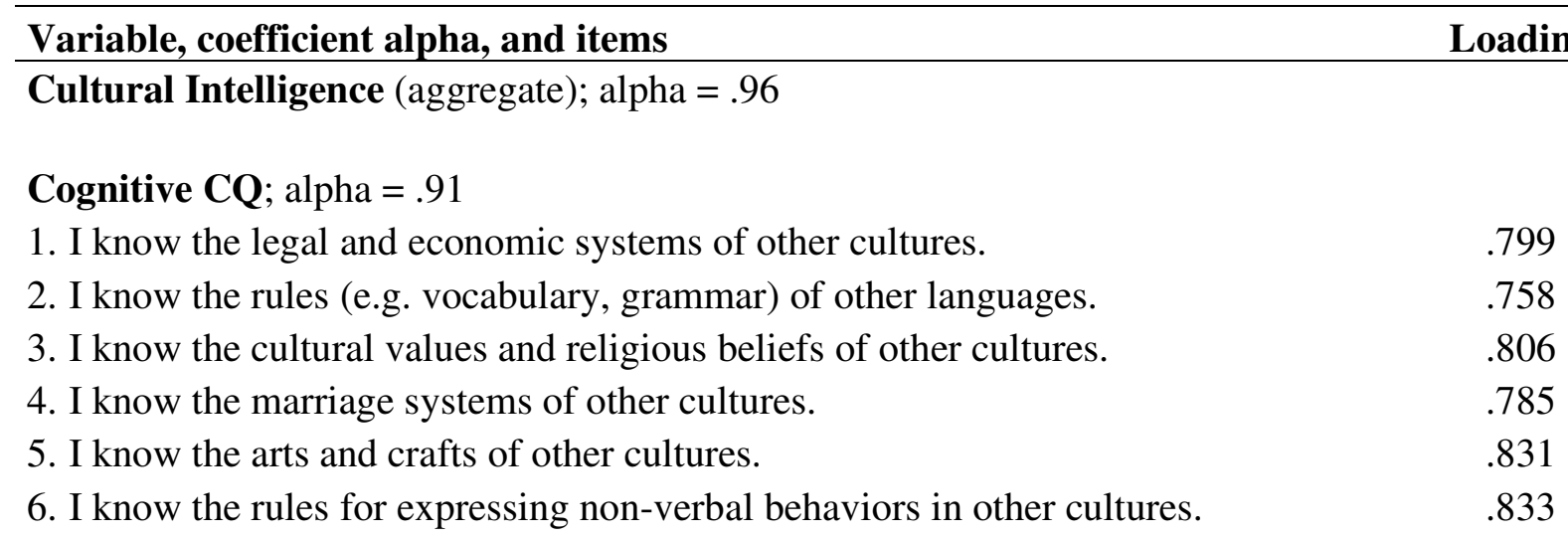

Metacognitive CQ; alpha $=.89$

1. I am conscious of the cultural knowledge I use when interacting with people with different cultural backgrounds.

2. I adjust my cultural knowledge as I interact with people from a culture that is unfamiliar to me.

3. I am conscious of the cultural knowledge I apply to cross-cultural interactions. $\quad .816$

4. I check the accuracy of my cultural knowledge as I interact with people from different cultures.

Motivational CQ; alpha $=.89$

1. I enjoy interacting with people from different cultures.

2. I am confident that I can socialize with locals in a culture that is unfamiliar to me. $\quad .783$

3. I am sure I can deal with the stresses of adjusting to a culture that is new to me. $\quad .839$

4. I enjoy living in cultures that are unfamiliar to me. $\quad .775$

5. I am confident that I can get used to the shopping conditions in a different culture. $\quad .853$

Behavioral CQ; alpha $=.91$

1. I change my verbal behavior (e.g. accent, tone) when a cross-cultural interaction requires it.

2. I use pause and silence differently to suit different cross-cultural situations. $\quad .833$

3. I vary the rate of my speaking when a cross-cultural situation requires it. $\quad .776$

4. I change my non-verbal behavior when a cross-cultural situation requires it. $\quad .872$

5. I alter my facial expressions when a cross-cultural interaction requires it. $\quad .817$ 
Adaptive Selling Behavior; alpha $=.91$

1. When I feel that my sales approach is not working, I can easily change to another approach.

2. I like to experiment with different sales approaches.

3. I am very flexible in the selling approach I use.

4. I can easily use a wide variety of selling approaches.

5. I try to understand how one customer differs from another.

Intrinsic Motivation; alpha $=.81$

1. Trying to sell to new customers is funny for me.

2. Getting new customers is a challenge and a stimulant thing.

3. For me it is a challenge to find the way to sell the product to the customer. 582

4. I feel pretty good when I make a sale.

Role Ambiguity; alpha $=.89$

1. I have clear, planned goals and objectives for my job. (R)

2. I know I have divided my time properly while performing the tasks connected with my job. (R)

3. I know what my responsibilities are in my job. (R)

4. I receive clear explanations of what has to be done in my job. $(\mathrm{R})$

Ethnocentrism; alpha $=.97$

1. Other cultures should try to be more like my culture.

2. I am not interested in the values and customs of other cultures.

3. Most people from other cultures just do not know what is good for them.

4. I have little respect for the values and customs of other cultures.

5. Most people would be happier if they lived like people in my culture.

6. Lifestyles in other cultures are not as valid as those in my culture. $\quad .890$

7. I do not cooperate with people who are different. $\quad .923$

8. I do not trust people who are different. $\quad .916$

9. I dislike interacting with people from different cultures. $\quad .893$

10.Other cultures are smart to look up to our culture. $\quad .810$ 
Table 2 Average variance extracted (AVE), composite reliability, and squared correlations

\begin{tabular}{|c|c|c|c|c|c|c|c|c|c|c|}
\hline \multirow[t]{2}{*}{ Variable } & \multirow{2}{*}{$\begin{array}{l}\text { Composite } \\
\text { reliability }\end{array}$} & \multirow[t]{2}{*}{ AVE } & \multicolumn{8}{|c|}{ Squared correlations } \\
\hline & & & CCQ & MCCQ & MCQ & BCQ & ETHN & RA & IM & ASB \\
\hline Cognitive_CQ (CCQ) & 0.915 & 0.644 & - & & & & & & & \\
\hline Metacognitive_CQ (MCCQ) & 0.890 & 0.699 & 0.809 & - & & & & & & \\
\hline Motivational_CQ (MCQ) & 0.896 & 0.637 & 0.666 & 0.715 & - & & & & & \\
\hline Behavioral_CQ (BCQ) & 0.909 & 0.667 & 0.551 & 0.679 & 0.733 & - & & & & \\
\hline Ethnocentrism (ETHN) & 0.967 & 0.751 & 0.061 & 0.006 & 0.007 & 0.01 & - & & & \\
\hline Role Ambiguity (RA) & 0.887 & 0.669 & 0.165 & 0.248 & 0.253 & 0.18 & 0.006 & - & & \\
\hline Intrinsic Motivation (IM) & 0.815 & 0.553 & 0.130 & 0.263 & 0.245 & 0.248 & 0.012 & 0.584 & - & \\
\hline $\begin{array}{l}\text { Adaptive Selling Behavior } \\
\text { (ASB) }\end{array}$ & 0.911 & 0.672 & 0.277 & 0.449 & 0.427 & 0.41 & 0.008 & 0.438 & 0.528 & - \\
\hline
\end{tabular}


Table 3 Means, standard deviations, and correlations

\begin{tabular}{|c|c|c|c|c|c|c|c|c|c|c|c|c|c|c|c|}
\hline Variable & Mean & SD & 1 & 2 & 3 & 4 & 5 & 6 & 7 & 8 & 9 & 10 & 11 & 12 & 13 \\
\hline 1 Cultural intelligence & 5.09 & 1.20 & 1.00 & & & & & & & & & & & & \\
\hline 2 Cognitive CQ & 4.71 & 1.42 & $.91 * *$ & 1.00 & & & & & & & & & & & \\
\hline 3 Metacognitive CQ & 5.31 & 1.31 & $.91 * *$ & $.81^{* *}$ & 1.00 & & & & & & & & & & \\
\hline 4 Motivational CQ & 5.33 & 1.27 & $.90 * *$ & $.74 * *$ & $.76^{* *}$ & 1.00 & & & & & & & & & \\
\hline 5 Behavioral CQ & 5.16 & 1.31 & $.88^{* *}$ & $.68^{* *}$ & $.74 * *$ & $.78^{* *}$ & 1.00 & & & & & & & & \\
\hline 6 Ethnocentrism & 2.13 & 1.18 & $.15^{* *}$ & $.24 * *$ & .07 & .08 & 0.1 & 1.00 & & & & & & & \\
\hline 7 Intrinsic motivation & 5.94 & 1.04 & $.44 * *$ & $.31 * *$ & $.43^{* *}$ & $.43^{* *}$ & $.43^{* *}$ & -.05 & 1.00 & & & & & & \\
\hline 8 Role ambiguity & 2.01 & 1.04 & $-.45^{* *}$ & $-.36 * *$ & $-.44 * *$ & $-.45 * *$ & $-.38^{* *}$ & 0.06 & $-.63 * *$ & 1.00 & & & & & \\
\hline 9 Sales experience & 10.22 & 8.77 & -.07 & $-.13^{*}$ & -.01 & -.03 & -.05 & $-.18^{* *}$ & $.17^{* *}$ & -.05 & 1.00 & & & & \\
\hline 10 Age & 34.6 & 13.04 & -.09 & $-.19 * *$ & -.03 & -.03 & -.01 & $-.26^{* *}$ & $.21 * *$ & -.01 & $.67^{* *}$ & 1.00 & & & \\
\hline $\begin{array}{l}11 \begin{array}{l}\text { Adaptive selling } \\
\text { behavior }\end{array}\end{array}$ & 5.76 & 1.10 & $.62 * *$ & $.48 * *$ & $.61 * *$ & $.60^{* *}$ & $.58 * *$ & -.09 & $.62 * *$ & $-.59 * *$ & 0.1 & .08 & 1.00 & & \\
\hline 12 Cultural distance & 3.08 & 1.64 & .04 & .03 & .02 & .01 & .09 & -.04 & .07 & -.03 & .02 & .00 & .07 & 1.00 & \\
\hline $13 \begin{array}{l}\text { International } \\
\text { experience }\end{array}$ & 3.75 & 3.75 & $.25 * *$ & $.25^{* *}$ & $.24 * *$ & $.22^{* *}$ & $.18^{* *}$ & .01 & .09 & -.03 & .02 & .04 & .05 & .07 & 1.00 \\
\hline 14 Gender & 0.64 & 0.48 & .03 & .07 & .04 & .03 & -.03 & .04 & .06 & .05 & $.14^{*}$ & .10 & -.03 & .01 & .09 \\
\hline
\end{tabular}

Note: $* p<.05 . * * p<.01$ 
Figure 2 Results for regression model 2

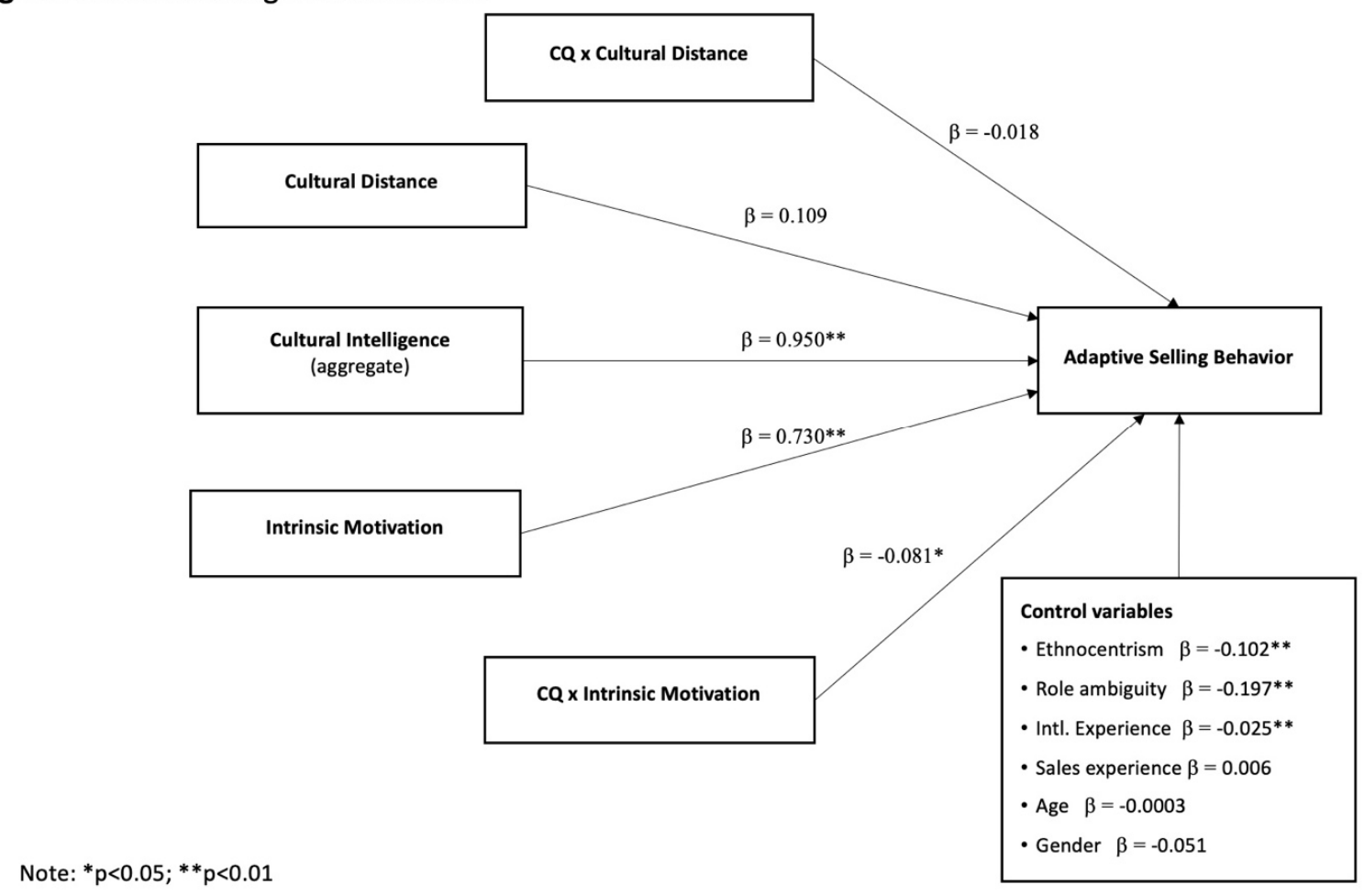

Figure 3 Results for regression model 4

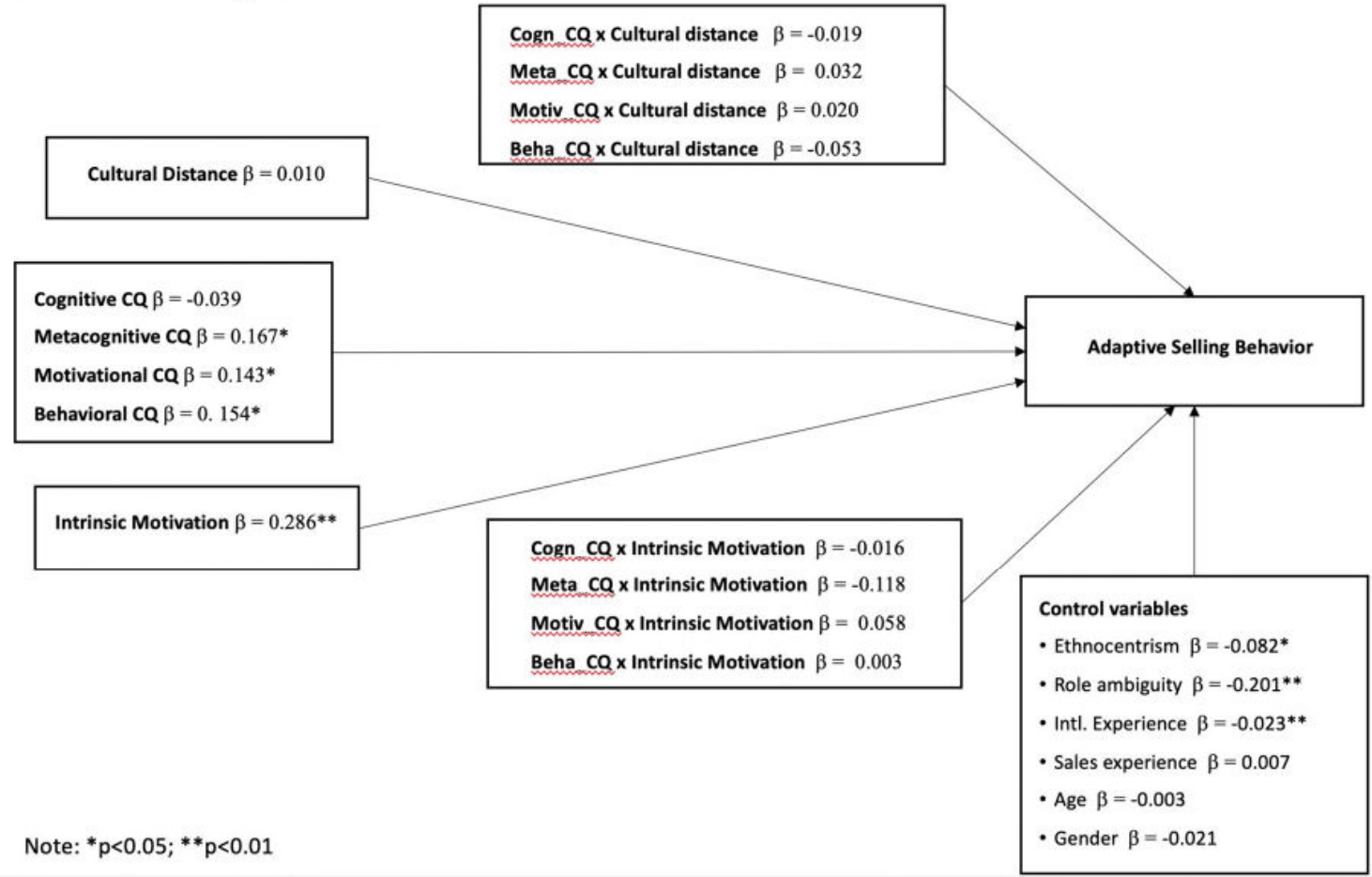


Table 4 Regression models: Antecedents of adaptive selling behavior

\begin{tabular}{|c|c|c|c|c|}
\hline \multicolumn{5}{|c|}{ Dependent variable: Adaptive Selling Behavior } \\
\hline Predictors & Model 1 & Model 2 & Model 3 & Model 4 \\
\hline Aggregate CQ & $0.417 * *$ & $0.950 * *$ & & \\
\hline Cognitive CQ & & & -0.047 & -0.039 \\
\hline Metacognitive CQ & & & $0.183^{*}$ & $0.167 *$ \\
\hline Motivational CQ & & & $0.150^{*}$ & $0.143 *$ \\
\hline Behavioral CQ & & & $0.150 *$ & $0.154 *$ \\
\hline Cultural distance & 0.017 & 0.109 & 0.017 & 0.010 \\
\hline Intrinsic motivation & $0.343 * *$ & $0.730 * *$ & $0.315 * *$ & $0.286 * *$ \\
\hline Ethnocentrism & $-0.099 * *$ & $-0.102 * *$ & $-0.077 *$ & $-0.082 *$ \\
\hline Role ambiguity & $-0.224 * *$ & $-0.197 * *$ & $-0.225^{* *}$ & $-0.201 * *$ \\
\hline Sales experience & 0.007 & 0.006 & 0.008 & 0.007 \\
\hline International experience & $-0.026^{* *}$ & $-0.025 * *$ & $-0.023^{* *}$ & $-0.023 * *$ \\
\hline Age & 0.0003 & -0.0003 & -0.003 & -0.003 \\
\hline Gender & -0.053 & -0.051 & -0.017 & -0.021 \\
\hline CQ x Cultural distance & & -0.018 & & \\
\hline CQ x Int_motivation & & $-0.081 *$ & & \\
\hline Cogn_CQ x Cultural distance & & & & -0.019 \\
\hline Meta_CQ x Cultural distance & & & & 0.032 \\
\hline Motiv_CQ x Cultural distance & & & & 0.020 \\
\hline Beha_CQ x Cultural distance & & & & -0.053 \\
\hline Cogn_CQ x Int_motivation & & & & -0.016 \\
\hline Meta_CQ x Int_motivation & & & & -0.118 \\
\hline Motiv_CQ x Int_motivation & & & & 0.058 \\
\hline Beha_CQ x Int_motivation & & & & 0.003 \\
\hline Intercept & $2.23 * *$ & -0.31 & $2.20 * *$ & $2.49 * *$ \\
\hline$R^{2}$ & .60 & .61 & .61 & .63 \\
\hline$\Delta R^{2}$ & & $.01 *$ & & .02 \\
\hline
\end{tabular}

Note: ${ }^{*} \mathrm{p}<.05 .{ }^{* *} \mathrm{p}<.01$ 